\title{
BMJ Open Consumption and effects of caffeinated energy drinks in young people: an overview of systematic reviews and secondary analysis of UK data to inform policy
}

\author{
Claire Khouja (10 , ${ }^{1}$ Dylan Kneale (1) , ${ }^{2}$ Ginny Brunton, ${ }^{3}$ Gary Raine, ${ }^{1}$ \\ Claire Stansfield, ${ }^{2}$ Amanda Sowden, ${ }^{1}$ Katy Sutcliffe, ${ }^{2}$ James Thomas ${ }^{2}$
}

To cite: Khouja C, Kneale D, Brunton $\mathrm{G}$, et al. Consumption and effects of caffeinated energy drinks in young people: an overview of systematic reviews and secondary analysis of UK data to inform policy. BMJ Open 2022;12:e047746. doi:10.1136/ bmjopen-2020-047746

- Prepublication history and additional supplemental material for this paper are available online. To view these files, please visit the journal online (http://dx.doi.org/10.1136/ bmjopen-2020-047746).

Received 07 December 2020 Accepted 14 December 2021

\section{Check for updates}

(c) Author(s) (or their employer(s)) 2022. Re-use permitted under CC BY-NC. No commercial re-use. See rights and permissions. Published by BMJ.

${ }^{1}$ Centre for Reviews and Dissemination, University of York, York, UK

${ }^{2}$ EPPI-Centre, Social Science Research Unit, UCL Institute of Education, University College London, London, UK

${ }^{3}$ Faculty of Health Sciences, Ontario Tech University, Oshawa, Ontario, Canada

Correspondence to

Claire Khouja;

claire.khouja@york.ac.uk

\section{ABSTRACT}

Background This overview and analysis of UK datasets was commissioned by the UK government to address concerns about children's consumption of caffeinated energy drinks and their effects on health and behaviour. Methods We searched nine databases for systematic reviews, published between 2013 and July 2021, in English, assessing caffeinated energy drink consumption by people under 18 years old (children). Two reviewers rated or checked risk of bias using AMSTAR2, and extracted and synthesised findings. We searched the UK Data Service for country-representative datasets, reporting children's energy-drink consumption, and conducted bivariate or latent class analyses.

Results For the overview, we included 15 systematic reviews; six reported drinking prevalence and 14 reported associations between drinking and health or behaviour. AMSTAR2 ratings were low or critically low. Worldwide, across reviews, from $13 \%$ to $67 \%$ of children had consumed energy drinks in the past year. Only two of the 74 studies in the reviews were UK-based. For the dataset analysis, we identified and included five UK cross-sectional datasets, and found that $3 \%$ to $32 \%$ of children, across UK countries, consumed energy drinks weekly, with no difference by ethnicity. Frequent drinking ( 5 or more days per week) was associated with low psychological, physical, educational and overall well-being. Evidence from reviews and datasets suggested that boys drank more than girls, and drinking was associated with more headaches, sleep problems, alcohol use, smoking, irritability, and school exclusion. GRADE (Grading of Recommendations, Assessment, Development and Evaluation) assessment suggests that the evidence is weak.

Conclusions Weak evidence suggests that up to a third of children in the UK consume caffeinated energy drinks weekly; and drinking 5 or more days per week is associated with some health and behaviour problems. Most of the evidence is from surveys, making it impossible to distinguish cause from effect. Randomised controlled trials are unlikely to be ethical; longitudinal studies could provide stronger evidence.
Strengths and limitations of this study

- The main strength of this study was the novel use of a secondary data analysis to fill a gap in the evidence that was identified by the overview.

- A strength of the overview was its robust methods, and that it only included reviews that used systematic methods.

- A limitation of the overview was the strength of evidence of the primary research, most of which was from cross-sectional surveys.

- The main limitations of the dataset analysis were that longitudinal data were not available, and the survey data could not be combined due to differences between surveys in their designs and measures reported.

PROSPERO registrations CRD42018096292 - no deviations. CRD42018110498 - one deviation - a latent class analysis was conducted.

\section{INTRODUCTION}

Caffeinated energy drinks (CEDs) are drinks containing caffeine, among other ingredients, that are marketed as boosting energy, reducing tiredness, and improving concentration. They include brands such as Red Bull, Monster Energy, and Rockstar. There is widespread concern about their consumption and effects in children and adolescents (under 18 years old). ${ }^{1-4}$ Some professional organisations have suggested banning sales to children. ${ }^{2}$ In the UK, warnings, aimed at children and pregnant women, are required on the packaging for drinks that contain over 150 $\mathrm{mg} / \mathrm{L}$ of caffeine. ${ }^{5}$ An average $250 \mathrm{~mL}$ energy drink contains a similar amount of caffeine to a $60 \mathrm{~mL}$ espresso, and the European Food Safety Authority proposes a safe level of $3 \mathrm{mg}$ 
of caffeine per kg of body weight per day for children and adolescents. ${ }^{6}$ Many drinks also contain other potentially active ingredients, such as guarana and taurine, and more sugar than other soft drinks, although there are sugarfree options. ${ }^{7-9}$ Children may be more at risk of ill effects than adults. ${ }^{1011}$ Effects could be physical (eg, headaches), psychological (eg, anxiety) or behavioural (eg, school attendance or alcohol consumption). ${ }^{12}$ Available systematic reviews report a wide range of findings, including positive effects on sports performance.

In 2018, the UK government ran a consultation on implementing a ban on sales to children, ${ }^{13-15}$ and in March 2019 they published a policy paper. ${ }^{16}$ The research reported here was commissioned by the Department of Health and Social Care (DHSC), England, in 2018, to identify and assess the evidence on the use of CEDs by children. As the deadline was short, and as initial searches identified several systematic reviews, a systematic review of systematic reviews (referred to as overview, from this point onwards) was conducted. As only two UK studies were identified within the reviews included in the overview, UK datasets were sought, and a secondary analysis of relevant data was carried out to supplement the international literature and ensure relevance to UK policy. Full reports are available. ${ }^{1718}$

The research questions $(\mathrm{RQ})$ were:

RQ1. What is the nature and extent of CED consumption among people aged 17 years or under in the UK?

RQ2. What impact do CEDs have on young people's physical and mental health, and behaviour?

\section{METHODS}

This paper summarises the overview and dataset analysis. ${ }^{17} 18$ For the overview, a literature search was conducted during May 2018 and updated on 2 July 2021. EPPI-Reviewer software ${ }^{19}$ was used to manage the data. The gaps, identified by the overview and a search for primary studies, guided the search, conducted during August 2018, for UK datasets and their subsequent analysis. STATA v $13^{20}$ was used to analyse the datasets. Ethical approval was granted by UCL's Ethics Committee. Protocols were registered on PROSPERO (CRD42018096292 and CRD42018110498).

\section{Search strategies}

For the overview, we searched nine databases, focusing on research in health, psychology, science or social science, or general research. We completed forward citation searching in Google Scholar for 13 included reviews. The databases searched and the MEDLINE search strategy are in the online supplemental file (section 1). The search terms were based on three concepts: caffeine, energy drink, and systematic review. The searches were limited to the publication year of 2013 onwards, to identify the most recent systematic reviews. For the dataset analysis, search terms were based on caffeine and energy drink.
We searched the UK Data Service ${ }^{21}$ (accessing over 6000 UK nation population datasets), with no restrictions.

\section{Inclusion criteria}

For the overview:

- Systematic review published since 2013

- Extractable data on children under 18 years of age

- Available in English

- Patterns of CED use or associations with physical, mental, social or behavioural effects.

Four reviewers (GB, CK, GR and CS) screened references based on their titles and abstracts, and then screened potential includes on their full texts. The four reviewers double-screened batches of 10 references until their decisions to include or exclude each paper were the same on at least nine of the 10 (90\%), then they screened individually. Disagreements and indecisions were resolved by another of the four reviewers, where necessary.

For the dataset analysis:

- Downloadable datasets, representative of the UK or a constituent country

- Information on the levels and patterns of CED consumption

- Data on children under 18 years of age (adults could provide the data on their behalf)

- Reporting primary (frequency, amount, or occurrence of drinking/not drinking (comparator)) or secondary (sugar consumption, cardiovascular health, mental health, neurological conditions, educational outcomes, substance misuse, sports performance or sleep characteristics) measures.

After a pilot batch, for which two reviewers (GB and DK) assessed datasets independently and discussed their decisions to include or exclude, the remaining datasets were screened, independently.

\section{Data extraction}

From the systematic review reports that met the overview inclusion criteria, we extracted details on/for: systematic review methods; included studies; CED consumption; associations with physical, mental, social or behavioural effects; and risk of bias assessment. One reviewer (GB, CK, GR or CS) extracted these data, which were checked by another reviewer. For the dataset analysis, one reviewer (GB or DK) extracted dataset characteristics (sample size, etc); details on participants (age, gender, etc) and consumption (how it was measured, etc); well-being and health outcomes, including potential confounders; and information on missing data and for risk of bias assessment.

\section{Syntheses}

The data extracted from the systematic reviews were synthesised in a narrative format due to variation between reviews. Prevalence was synthesised by the measure used, where possible. Associations were synthesised by whether they were physical, mental, behavioural, or social/educational, and summary tables were produced. One reviewer 
(GB, CK, GR or CS) synthesised the data and another checked each synthesis.

Each dataset was analysed for prevalence and frequency of CED consumption, and any variations by children's characteristics. Most of the cross-sectional analyses were bivariate (exploring interactions between two features), with binary and multinomial logistic regression used to control for confounders. A latent class analysis (LCA) was conducted, ${ }^{22}$ for one dataset. The latent profiles were based on children's health experiences, such as headaches, anxiety, or dizziness. The observed variables (11 indicators of child well-being) and latent variables (five classes of well-being) were identified from the data. Class membership was used as the dependent variable in multinomial logistic regressions. Descriptive associations were explored in bivariate analyses of the 11 indicators, separately. The results from individual datasets were synthesised in a narrative because meta-analysis was not deemed to be appropriate. Missing data were not imputed, as it was not possible to determine if they were missing at random. One reviewer (DK) analysed the data.

\section{Risk of bias}

AMSTAR2 ${ }^{23}$ was used to assess the risk of bias in the included systematic reviews, because some reviews included randomised controlled trials (RCTs) as well as non-RCTs. AMSTAR2 has questions on the protocol, inclusion criteria, search, selection, data extraction, risk of bias assessment, reporting, synthesis (RCTs and nonRCTs), and conflicts of interest; a question on relevance was added. The strength of the evidence was assessed using GRADE (Grading of Recommendations, Assessment, Development and Evaluation) criteria, ${ }^{24}$ which can be used to determine whether the evidence is strong or weak, based on any risk of bias, including in study design and size, consistency of the results, relevance to the population, and potential publication bias. Overlap, where the same primary studies appear in more than one review, was assessed..$^{25}$ Overlap can lead to double counting of the results of a study, giving these more influence than those of other studies. ${ }^{26}$ Two reviewers (CK and GR) assessed risk of bias; random samples were checked by a third reviewer (GB). Datasets were not formally assessed, but all datasets met the quality assurance criteria of the UK Data Service. ${ }^{27}$ Data on exposure (quantity, frequency and type of drink), sample frame (characteristics of participants), and level of participation (response rate) were extracted, by one reviewer (DK), to determine their parameters. ${ }^{17}$ In line with National Institutes of Health guidance, ${ }^{28}$ no overall risk of bias score was produced for each dataset because overall scores can be misleading where the risk of bias on each criterion has a different impact on the reliability of the conclusions.

\section{Patient and public involvement}

We did not include young people in the research process.

\section{RESULTS}

The overview searches identified 1102 references, after deduplication (see figure 1); 126 were screened on full texts. We included 15 reviews; six reported information on prevalence, ${ }^{12} 29-33$ and 14 reported associations. ${ }^{129-32}$ 34-42 The reasons for exclusion, based on assessment of the full text, are reported in the online supplemental file (section 2). Most were excluded because they did not use systematic review methods or did not report information on children.

Three reviews focused on CEDs in children. ${ }^{123041} \mathrm{One}^{35}$ focused on children, with a section on CEDs alongside other drinks. The other 11 reported information on children alongside data for adults; one ${ }^{29}$ with CEDs alongside other drinks, and two ${ }^{3132}$ focusing on alcohol mixed with CEDs. For summary and full characteristics, see the online supplemental file (section 3) and the full report. ${ }^{18}$

For the dataset analysis, as there was no facility to export results, it was not possible to record the flow of datasets through screening. Five datasets met the inclusion criteria; analyses were not possible for one dataset ${ }^{43}$ (see table 1). For full descriptions, see the full report. ${ }^{17}$

\section{Risk of bias}

There was a high risk of bias in all but three of the reviews-Visram et al, ${ }^{12}$ and Bull et $a l^{37}$ Yasuma $e t a l^{11}$ (details in the online supplemental file, section 4)meaning that some relevant evidence may have been missed. Overlap between studies in the reviews was slight (corrected covered area 3.2\%; see the online supplemental file, section 5). The reviews did not include any analyses of the UK datasets that we analysed. Within the reviews, there were four small randomised controlled trials, while most studies were surveys with a high risk of bias; the application of GRADE criteria, which are used to assess the overall strength of the evidence found, suggests that the evidence is weak. Exposure, sample frame and level of participation for the datasets are reported in appendix 1 of the full report. ${ }^{17}$

\section{UK studies in the overview}

Of the 74 studies identified by the reviews that are summarised in the overview, two were UK surveys. One $^{44-46}$ was a longitudinal (two time-points) crosssectional survey of 11- to 17-year-olds in the south-west of England. The other ${ }^{47}$ was a survey of 13- to 18 -year-olds across 22 European countries, one of which was the UK (2.6\% of respondents).

Below and in tables 2-4, the overview results are summarised by research question, followed by highlights of the dataset analysis within each topic. The full results of the overview ${ }^{18}$ and dataset analysis ${ }^{17}$ are available online.

\section{RQ1. Nature and extent of CED consumption}

The overview included six reviews with data on prevalence of children's CED consumption, and these are summarised in table 2. 




Figure 1 Flow diagram for the overview. CED, caffeinated energy drinks; T\&A, title and abstract.

Across reviews, prevalence varied by study location, population age range, and definition of drinking (ever drunk, in the past year, regularly, with alcohol, etc) from $13 \%$ to $67 \%$ of children having a CED in the past year. $^{30}{ }^{32}$ One meta-analysis ${ }^{29}$ of four studies in the Gulf states suggested that about two thirds of children consumed CEDs (not further defined; $65.3 \%, 95 \%$ CI 41.6 to 102.3 (as reported in the paper)). Across reviews, weekly or monthly drinking ranged from $13 \%$ to $54 \%$ of children. In one study, across Europe, UK children had the highest proportion of caffeine intake from CEDs, at $11 \%,{ }^{47}$ but this might reflect a lower intake from coffee or tea. Across reviews, $10 \%{ }^{49}$ to $46 \%{ }^{50}$ of children had tried CEDs with alcohol.

In the UK dataset analysis, self-reported prevalence was relatively consistent across UK countries (see table 3), although there were differences in the questions asked. About a quarter of children aged 13 to 14 years consumed

\begin{tabular}{|c|c|c|c|c|}
\hline Dataset & Abbreviation & Region & Collection period(s) & Ages (years) \\
\hline Millennium Cohort Study (longitudinal) ${ }^{\star 43}$ & MCS & UK & 2008 & 9 months, $3,5,7,11,14,17$ \\
\hline Health Behaviour in School Children (Wales) $\dagger^{65}$ & HBSC & Wales & $2013 / 14$ and $2017 / 18$ & 11,13 and 15 \\
\hline National Diet and Nutrition Survey ${ }^{66}$ & NDNS & UK & 2014 to 2016 & 1.5 to 18 \\
\hline
\end{tabular}

*Only collected data on CED consumption at age 7 years (2008). Fewer than five parents reported that their child (out of $>13500$ children) would drink CEDs between meals and the data were not used in analyses.

†Used to explore associations with hypothesised antecedents or consequences of CED consumption.

CED, caffeinated energy drinks. 
Table 2 Characteristics and main findings of reviews reporting prevalence of consumption

\begin{tabular}{|c|c|c|}
\hline Review details & Methods and study details & $\begin{array}{l}\text { Main findings on prevalence, and } \\
\text { associated characteristics ( } \% \text { of children) }\end{array}$ \\
\hline \multicolumn{3}{|l|}{ Children or young people } \\
\hline $\begin{array}{l}\text { Reference: Dawodu }(2017)^{30} \\
\text { Exposure: CEDs } \\
\text { Age: } 10 \text { to } 18 \text { years }\end{array}$ & $\begin{array}{l}\text { Included: } 12 \text { surveys ( } 4 \text { on prevalence) } \\
\text { Published: } 2013 \text { to } 2015 \\
\text { Risk of bias tool: None }\end{array}$ & $\begin{array}{l}\text { Higher for boys than girls } \\
\text { In the past year - } 62 \% \text { or } 67 \% \\
\text { Once a month or more - } 20 \% \\
\text { Recent (undefined) }-13 \% \\
\text { Ever with alcohol }-10 \% \\
\text { Weekly - } 15 \% \text { or } 16 \%\end{array}$ \\
\hline
\end{tabular}

Children and adults (subsection on children)

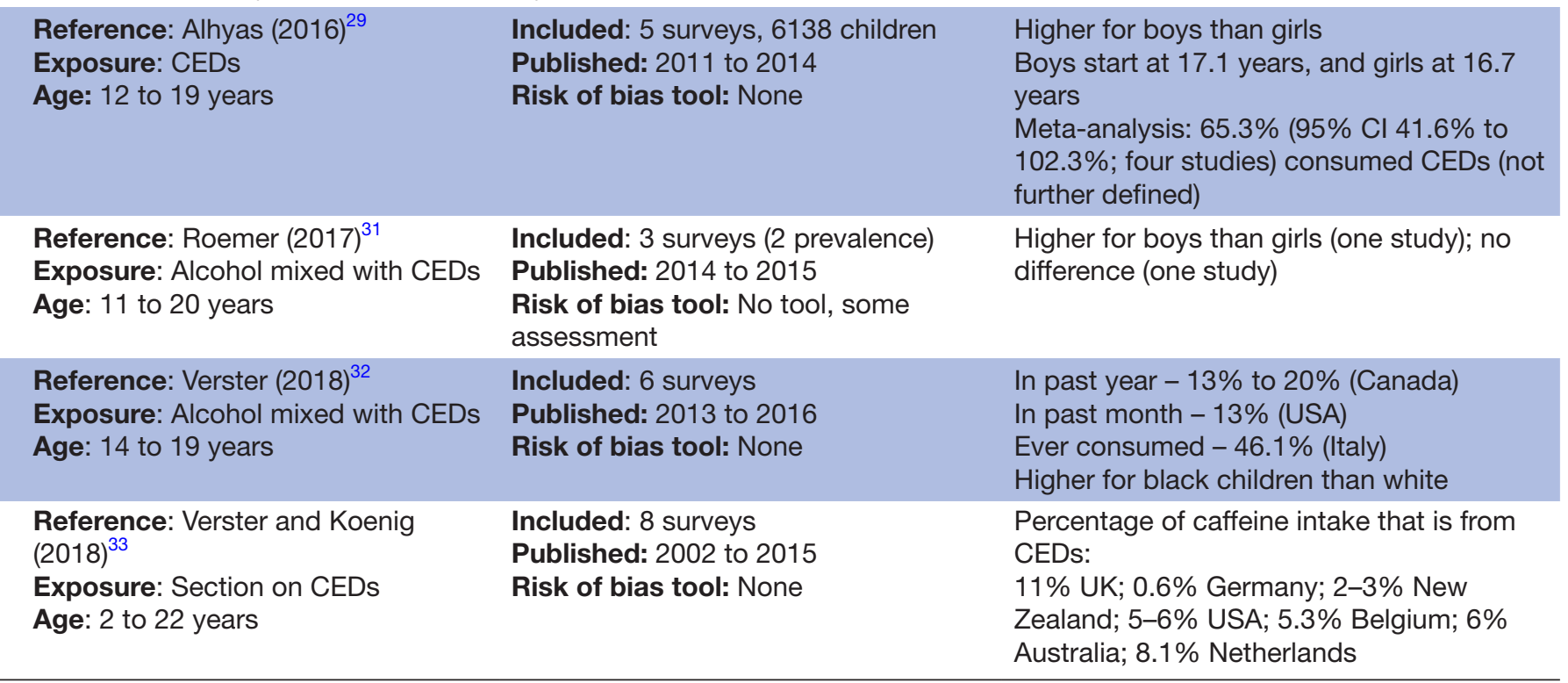

CASP, Critical Appraisal Skills Programme; CEDs, caffeinated energy drinks; EPHPP, Effective Public Healthcare Panacea Project; RCTs, randomised controlled trials.

one drink or more per week (Smoking and Drinking Survey of Young People (SDSYP) data). ${ }^{51}$ Prevalence ranged from $3 \%$ to $32 \%$ of children-slightly lower than found in the overview.

\section{Characteristics of drinkers}

In the overview, more boys reported drinking CEDs than girls. ${ }^{129-32}$ Prevalence by age was inconsistent: for example, within the reviews, one study ${ }^{48}$ found that girls started drinking CEDs when they were younger; while one $^{52}$ suggested that drinking prevalence peaked at 14 to 15 years; and another ${ }^{53}$ suggested that more older boys drank CEDs than younger boys, but more younger girls drank them than older girls. Prevalence by ethnicity was also inconsistent. Children with minority ethnicity drank more than white children, ${ }^{12}{ }^{32}$ but white children drank more than black or Hispanic children, when drinks were mixed with alcohol. ${ }^{12}$ In the UK, drinking was associated with being male, older and lower socioeconomic status. ${ }^{45}$

In the dataset analysis, the SDSYP reported the most detailed information on sociodemographic characteristics. As in most of the overview evidence, prevalence increased with age, so that between a quarter and a third of children aged 15 to 16 years reported consuming one or more CED per week. More boys (29.3\%) than girls $(18.1 \%)$, and more children living in the North of England than in the South (for example, $33.1 \%$ in the North-East vs $16.5 \%$ in the South-East), consumed at least one can a week. More children who were eligible for free school meals $(29.5 \%)$, than those who were not eligible $(22.6 \%)$, drank CEDs weekly. These differences were 
Table 3 Prevalence of CED consumption across datasets by school year (approximately weekly consumption with weighted percentages and unweighted sample sizes - see notes below)

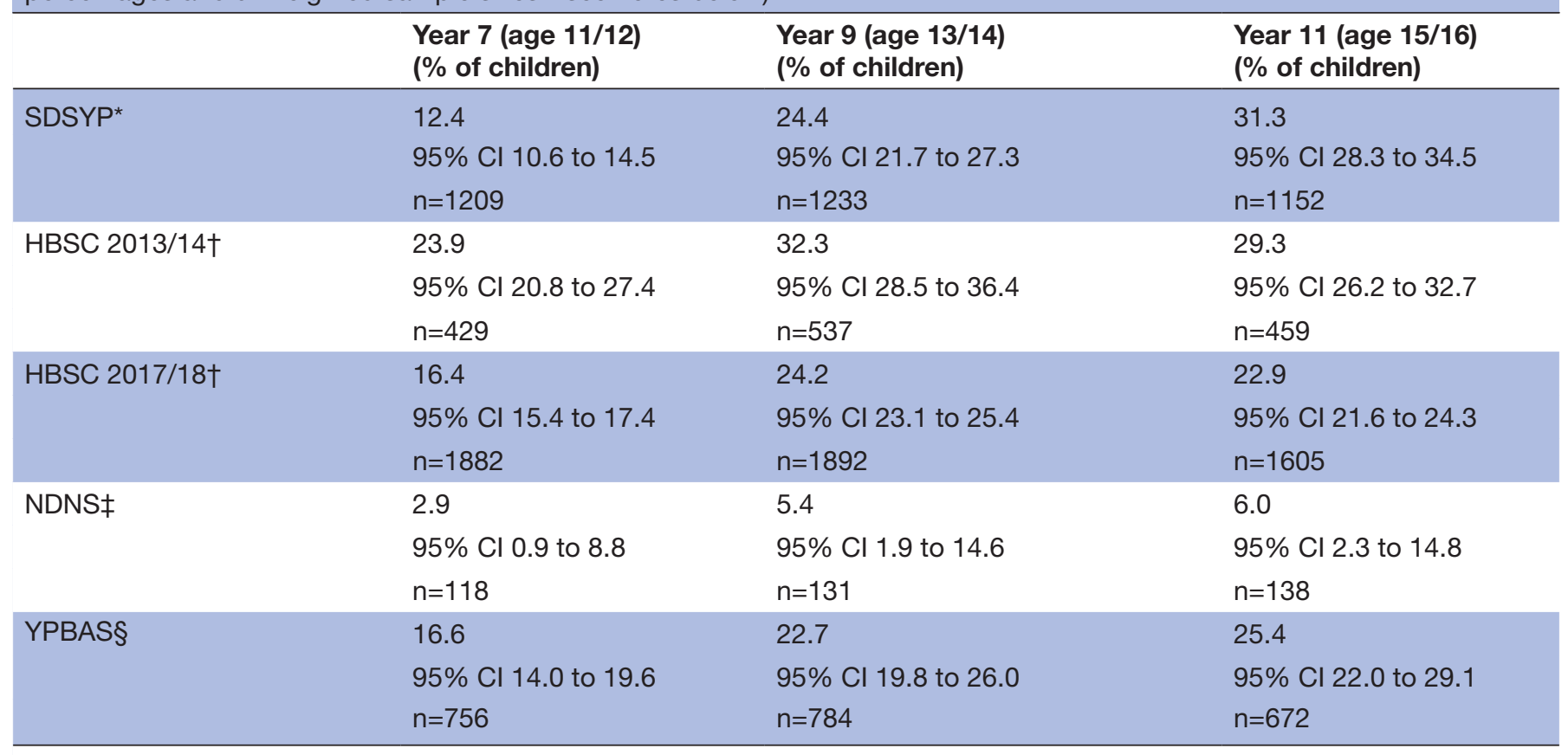

*Measured if children consumed at least one can of CED per week.

†Measured if children drank CED at least 1 day per week; differences in the sampling frame between the two data collection waves (2013/14 and 2017/18) make direct comparison challenging; in the later survey, sample weights were not available for all cases and these findings are only indicative.

‡Data collected through food diaries over a 4 day period.

$\S$ Measured if children drank CED at least 1 day per week.

CED, caffeinated energy drink; HBSC, Health Behaviour in School Children; NDNS, National Diet and Nutrition Surve; SDSYP, Smoking and Drinking Survey of Young People; YPBA, Young Persons' Behaviour and Attitudes.

robust to the impact of potential confounders (see the online supplemental file, section 6). Unlike the evidence from the overview, which suggested differences in consumption by ethnicity, the proportion of weekly CED consumers was within 3 percentage points of the average across all ethnic groups.

\section{Motives and context}

Three reviews reported on motives or context for consumption. ${ }^{12} 2932$ The context was parties and socialising with friends or family ${ }^{12} 3235$ or exams. ${ }^{29}$ Children's motives included taste (particularly with alcohol), for energy, curiosity, friends drinking them, and parental approval or disapproval. Across the reviews, single studies suggested that more girls than boys drank CEDs to suppress appetite, ${ }^{54}$ while more boys than girls drank them for performance in sport. ${ }^{55}$ And about half of children knew that the drinks contained caffeine, ${ }^{56}$ while those who knew that the content might be harmful drank less. $^{57}$

Motives and context were not measured in the UK datasets.

\section{RQ2. Associations with drinking CEDs}

Fourteen reviews reported associations and are summarised in table 4. Most reviews included crosssectional evidence (surveys) or individual case studies.
Three reviews ${ }^{12} 4042$ reported prospective trials (four small RCTs in total), which assessed physical performance, cardiovascular response, or the effects of sleep education; one review reported prospective cohort studies.

As most of the evidence was from surveys, measured at a single time-point, cause cannot be distinguished from effect.

\section{Physical health associations}

Associations between drinking CEDs and physical symptoms were reported in all but one ${ }^{40}$ of the 14 reviews. CEDs improved sports performance. ${ }^{58}{ }^{59}$ There was consistent evidence of associations with headaches, stomach aches and low appetite, ${ }^{12} 3542$ and with sleep problems. ${ }^{12} 303542$ Within the reviews, a trial of boys randomised to receive different doses of CED reported dose-dependent increases in diastolic blood pressure and decreases in heart rate. ${ }^{60}$ Across reviews, ${ }^{34}{ }^{36-39}$ nine cases of adverse events were reported; eight children had cardiovascular events, and one had renal failure, following a single drink, moderate drinking, or excessive drinking (in a day or for weeks).

Analysis of the Health Behaviour in School Children (HBSC) 2013/14 data found that children drinking CEDs once a week or more, compared with those drinking less often, were statistically significantly more likely to report physical symptoms occurring more than once a week, such 
Table 4 Characteristics and main findings of the reviews reporting associations with consumption

\begin{tabular}{lll} 
Review details $\quad$ Methods and study details & Main findings on associations \\
\hline
\end{tabular}

Reviews of children or young people

Reference: Visram (2016) ${ }^{12}$

Exposure: CEDs

Age: 10 to 21 years
Included: 46 studies (RCTs, surveys and

Published: 2003 to 2016

Risk of bias tool: CASP and EPHPP qualitative)

\author{
Reference: Dawodu (2017) \\ Exposure: CEDs \\ Age: 10 to 18 years \\ Included: 12 surveys \\ Published: 2013 to 2015
}

Physical: sports performance (2 RCTs), headache, sleep issues, fatigue, stomach aches, hyperactivity, blood pressure (1 $\mathrm{RCT})$

Mental: depression, traumatic experiences Behaviour: sensation seeking, drugs, alcohol, smoking

Social: academic performance

Physical: sleep issues, executive function, hyperactivity, inattention

Mental: anxiety, depression, anger, impulsivity, self-harm, suicide behaviour Behaviour: risk taking (alcohol, drug taking smoking)

Social: NA

Reference: Bleich and Vercammen Included: 7 or 8 surveys $(2018)^{35}$

Exposure: Soft drinks (subsection Risk of bias tool: None on CEDs)

Age: 10 to 18 years

\author{
Reference: Yasuma $(2021)^{41}$ \\ Exposure: CEDs \\ Age: 11 to 19 years
}

Published: 2014 to 2016
Physical: sleep issues, headaches, stomach aches, appetite

Mental: depression, stress, suicide behaviour

Behaviour: risk taking (smoking, drugs), ADHD, inattention

Social: NA

\section{Physical: NA}

Mental: NA

Behaviour: alcohol, smoking, drug use Social: NA
Risk of bias tool: ROBINS-I

Reviews of children and adults (subsection on children)
Reference: Alhyas (2016) ${ }^{29}$
Exposure: CEDs
Age: 12 to 19 years

\author{
Reference: Roemer (2017) ${ }^{31}$ \\ Exposure: Alcohol mixed with \\ CEDs \\ Age: 11 to 20 years \\ Included: 3 surveys \\ Published: 2014 to 2015 \\ Risk of bias tool: No tool, some \\ assessment
}

Included: 6 surveys

Published: 2013 to 2016

Risk of bias tool: None CEDs

Age: 14 to 19 years

Included: 7 surveys, 1 RCT

Published: 2010 to 2015

Risk of bias tool: None
Physical: increased energy level, voice tone changes, menstrual changes Mental: mood changes

Behaviour: NA Social: NA

Physical: traumatic brain injuries, alcoholrelated injuries, car crashes

Mental: NA

Behaviour: unsafe driving, binge drinking Social: NA

Physical: traumatic brain injury Mental: no differences in mental health Behaviour: risky behaviour (drugs, alcohol, smoking, violence, sexual behaviour) Social: school absence, academic achievement (some studies found no association)

Physical: NA

Mental: post-traumatic stress disorder, stress, anxiety, depression (some studies found no effect), self-harm, suicidal thoughts, and well-being

Behaviour: Improvements in behaviour and mental health with better sleep (and fewer CEDs - in an RCT)

Social: NA 


\begin{tabular}{lll}
\hline Table 4 Continued & & \\
\hline Review details & Methods and study details & Main findings on associations \\
\hline Reference: Nadeem (2021) & Included: 9 surveys, 1 RCT & Physical: cardiovascular, gastrointestinal, \\
Exposure: CEDs & Published: 2014 to 2018 & immune, muscular, neurological, \\
Age: 11 to 19 years & Risk of bias tool: MINORS & physiological, renal (ranging from 8-35\% of \\
& & children) \\
& & Mental: stress, depression, and suicidal \\
& & thoughts/attempt (20-35\% of children) \\
& & Behaviour: NA \\
& & Social: NA
\end{tabular}

Reviews of case reports (excluding adults)

$\begin{array}{lll}\text { Reference: } \text { Ali }(2015)^{34} & \text { Included: } 4 \text { cases (all male) } & \text { Physical: palpitations, angina } \\ \text { Exposure: CEDs } & \text { Published: } 2011 \text { to } 2012 & \text { Mental: NA } \\ \text { Age: } 13 \text { to } 17 \text { years } & \text { Risk of bias tool: None } & \text { Behaviour: NA }\end{array}$

$\begin{array}{ll}\text { Reference: Buck }(2013)^{36} & \text { Included: } 3 \text { cases } \\ \text { Exposure: CEDs } & \text { Published: } 2008 \text { to } 2012 \\ \text { Age: } 13 \text { to } 16 \text { years } & \text { Risk of bias tool: None }\end{array}$

\begin{tabular}{|c|c|c|}
\hline $\begin{array}{l}\text { Reference: Bull }(2015)^{37} \\
\text { Exposure: CEDs } \\
\text { Age: } 10 \text { to } 17 \text { years }\end{array}$ & $\begin{array}{l}\text { Included: } 2 \text { cases } \\
\text { Published: } 2011 \\
\text { Risk of bias tool: None }\end{array}$ & $\begin{array}{l}\text { Physical: renal failure, jitteriness } \\
\text { Mental: NA } \\
\text { Behaviour: NA } \\
\text { Social: NA }\end{array}$ \\
\hline $\begin{array}{l}\text { Reference: Lippi }(2016)^{39} \\
\text { Exposure: CEDs } \\
\text { Age: } 13 \text { to } 17 \text { years }\end{array}$ & $\begin{array}{l}\text { Included: } 2 \text { cases } \\
\text { Published: } 2012 \text { to } 2013 \\
\text { Risk of bias tool: None }\end{array}$ & $\begin{array}{l}\text { Physical: ST elevation myocardial infarction } \\
\text { (angina, coronary artery dissection) } \\
\text { Mental: NA } \\
\text { Behaviour: NA } \\
\text { Social: NA }\end{array}$ \\
\hline
\end{tabular}

ADHD, attention deficit hyperactivity disorder; CASP, Critical Appraisal Skills Programme; CEDs, caffeinated energy drinks; EPHPP, Effective Public Healthcare Panacea Project; MINORS, methodological index for non-randomized studies; NA, not applicable; NR, not reported; RCT, randomised controlled trial; ROBINS-I, Risk Of Bias In Non-randomised Studies - of Interventions.

as headaches $(22.2 \%$ vs $16.8 \%)$, sleep problems $(13.6 \%$ vs $8.5 \%)$ and stomach problems $(31.2 \%$ vs $23.1 \%)$.

\section{Mental health associations}

Associations between drinking CEDs and mental health were inconsistent. ${ }^{12} 293032354042$ One review reported that improvements in mental health and hyperactivity were found in children who were randomised to receive an intervention to lower their intake of CEDs. ${ }^{61}$ Associations were found with stress, anxiety or depression, ${ }^{12} 30354042$ but two reviews ${ }^{12} 40$ also found studies that did not find an association. Some reviews included evidence of associations with self-harm or suicidal behaviour, ${ }^{30} 354042$ and with irritation and anger. ${ }^{12} 30354042$

Secondary analyses of the HBSC 2013/14 data found that children who consumed CEDs at least once a week were statistically significantly more likely, than those who did not, to report low mood $(20.3 \%$ vs $14.9 \%)$ and irritability $(30.8 \%$ vs $18.0 \%)$ on a weekly basis.

\section{Behavioural associations}

Some evidence of associations between drinking CEDs and behaviour was reported. ${ }^{12} 30-323542$ Drinking CEDs was associated with alcohol, smoking and substance misuse at a single time point, ${ }^{12} 3035$ and at follow-up. ${ }^{41}$ CED consumption at baseline predicted alcohol consumption at follow-up. ${ }^{12}$ Consumption was associated with increased hyperactivity and inattention, and with sensation seeking. ${ }^{12} 3035$ Injuries were associated with drinking CEDs with alcohol ${ }^{12} 31$ and without alcohol. $^{12} 30$

Analysis of the SDSYP data found that higher proportions of children who consumed one or more cans per week had tried alcohol (59.1\%) and smoking $(39.7 \%)$, 
compared with non-CED consumers (alcohol 28.9\%, smoking 10.4\%).

\section{Social or educational associations}

Consistent associations between drinking CEDs and social or educational outcomes were reported. ${ }^{1232}$ Within reviews, one UK study ${ }^{45}$ found an association between drinking CEDs once a week or more and poor school attendance. CEDs mixed with alcohol were associated with lower grades and more absence from school. ${ }^{32}$

Analysis of the SDSYP data found that almost half of children who had been truant or excluded reported drinking a can of CED on a weekly basis (49.5\%), compared with less than a fifth of those who had not been truant or excluded $(18.5 \%)$.

\section{Well-being profiles}

Using the HBSC 2013/14 dataset, we identified 11 indicators of well-being: weekly experience of irritability, sleep difficulties, nervousness, dizziness, headaches, stomach aches, and low mood; as well as low life satisfaction, feeling pressured by schoolwork some or a lot of the time, dislike of school, and low self-rated academic achievement. From these, using LCA, we identified five profiles: low psychological well-being (18.2\% of children), high overall well-being $(48.6 \%)$, low educational well-being (6.7\% of children), low physical well-being $(13.0 \%)$, and low overall well-being $(13.5 \%)$. See the online supplemental file (section 6) for details.

After controlling for age, gender, rurality, smoking status, alcohol status and Family Affluence Scale (a measure of socioeconomic status; for more information see Hartley et $a l^{62}$ ), the relative risk of having a low wellbeing profile, compared with a high well-being profile, was substantially higher for children who consumed CEDs at least 5 days a week (frequent), compared with those who rarely or never did. Relative to a high well-being profile, frequent consumers had a higher risk of low psychological well-being (RR 2.11, 95\% CI 1.56 to 2.85 ) and low physical well-being (RR 2.52, 95\% CI 1.76 to 3.61), and were over four times more likely to have low educational well-being (RR 4.81, 95\% CI 3.59 to 6.44 ) and low overall well-being (RR 4.15, 95\% CI 2.85 to 6.00 ). These data suggest that CED consumption is a marker of low wellbeing, but the analyses also showed that consumption was one of a cluster of factors (eg, smoking and drinking alcohol) in children with low well-being.

\section{DISCUSSION}

\section{Summary of the evidence}

Prevalence varied according to the measures used and the ages of children. In the overview, CED consumption prevalence was up to $67 \%$ of children in the past year and, in the dataset analyses, up to $32 \%$ of children were consuming a CED at least 1 day a week, meaning that up to a third of UK children are regularly consuming caffeine. Evidence from the overview and the dataset analyses consistently suggests that boys drink more than girls, and that drinking tends to increase with age. Some evidence from the overview suggested higher prevalence in children from ethnic minority backgrounds, but no such association was detected in the UK data analysis. This could be due to factors such as area of residence or social class affecting well-being in children from ethnic minorities, where well-being is driving the differences in prevalence of CED consumption, rather than minority background. Reviews included in the overview found that most drinking of CEDs occurred at parties, around exams, with friends, or with family, and motives included taste, energy, curiosity, appetite suppression, and sports performance, which was reported to be improved. There was some evidence that knowledge of content was low, and that children who knew that the content might be harmful drank less, suggesting that education could reduce drinking.

Evidence from the overview suggests worse sleep, and raised blood pressure, with CED consumption, compared with reduced or no consumption. Both the overview and the dataset analysis found that children who consumed CEDs reported headaches, stomach aches and sleep issues more frequently than those who did not; although most studies were cross-sectional, some in the overview were longitudinal, showing changes over time. ${ }^{18}$ The overview identified consistent evidence of associations with self-harm, suicide behaviour, alcohol use*, smoking*, substance misuse*, hyperactivity, irritation*, anger, and school performance, attendance, and exclusion (*also found in the UK dataset analysis). This was consistent with findings reported in non-systematic reviews. ${ }^{10} 6364$

The UK dataset analysis suggested that children who consumed CEDs 5 or more days a week had lower psychological, physical, educational and overall well-being than non-drinkers. It remains unclear whether drinking CEDs contributes to low well-being, or low well-being leads to CED consumption, or both. Alternatively, there may be a common cause, such as social inequality.

\section{Strengths and limitations}

The overview was limited by the amount of information reported in the included systematic reviews, and by their method limitations; all had a high risk of bias. They mainly included cross-sectional surveys or case reports, which means that cause or effect cannot be determined where an association is found. However, some prospective studies, including four small RCTs, were included in the reviews and where there were common measures, the evidence from these RCTs and from most of the crosssectional studies within the reviews was consistent. This suggests that the associations found could be reliable. A strength of our work is that the UK evidence in the overview (two studies within the reviews) was supplemented by the analysis of UK data, which was mostly consistent with the non-UK evidence. These data support the idea that there is a link between drinking CEDs and poorer health and behaviour in children, although the cause 
is unclear. Overlap between reviews in the overview was slight (unsurprisingly, given the different foci of the reviews). There was no overlap between the reviews and the dataset analysis, meaning that the latter added new information. The wide range of tools used to measure prevalence made it difficult to summarise the overview evidence, and meta-analysis of the individual participant UK data was not possible, meaning that the conclusions are based on weaker evidence from single sources.

\section{Recommendations for research}

Standardisation is needed in the measurement of the prevalence of drinking-defining the dosage (in drinks and/or caffeine), timing (daily, weekly, etc) and population (age, ethnicity, etc). There was little evidence on children under 12 years old, and both the overview and dataset analysis found little evidence from the UK. Longitudinal data, from the UK datasets, should be collected to understand better the impact of consumption. RCTs may not be ethical, even where benefits are predicted, such as where children who consume CEDs are randomised to interventions to reduce or stop their drinking to see if this improves their well-being.

\section{Conclusion}

Based on a comprehensive overview of available systematic reviews, we conclude that up to half of children, worldwide, drink CEDs weekly or monthly, and based on the dataset analysis, up to a third of UK children do so. There is weak but consistent evidence, from reviews and UK datasets, that poorer health and well-being is found in children who drink CEDs. In the absence of RCTs, which are unlikely to be ethical, longitudinal studies could provide stronger evidence.

\section{Twitter Katy Sutcliffe @katysutcliffe}

Acknowledgements Thank you to Irene Kwan for assisting with data extraction for the review.

Contributors GB, CK, GR and CS worked on all stages of the overview. GB, CK, DK and GR worked on the overview update. GB and DK completed all stages of the secondary data analysis. GB, KS, AS and JT supervised the work. All authors discussed the results and contributed to the final manuscript. JT is the guarantor of this work.

Funding This overview and secondary data analysis was funded by the National Institute for Health Research (NIHR) Policy Research Programme (PRP) for the Department of Health and Social Care (DHSC). It was funded through the NIHR PRP contract with the EPPI Centre at UCL (Reviews facility to support national policy development and implementation, PR-R6-0113-11003). Any views expressed in this publication are those of the author(s) and not necessarily those of the NHS, the NIHR or the DHSC.

Competing interests None declared.

Patient consent for publication Not applicable.

Ethics approval This study does not involve human participants.

Provenance and peer review Not commissioned; externally peer reviewed.

Data availability statement Data are available upon reasonable request. All the data in the overview are publicly available, but not necessarily without charge. Those for the dataset analysis are available from the UK Data Service.

Supplemental material This content has been supplied by the author(s). It has not been vetted by BMJ Publishing Group Limited (BMJ) and may not have been peer-reviewed. Any opinions or recommendations discussed are solely those of the author(s) and are not endorsed by BMJ. BMJ disclaims all liability and responsibility arising from any reliance placed on the content. Where the content includes any translated material, BMJ does not warrant the accuracy and reliability of the translations (including but not limited to local regulations, clinical guidelines, terminology, drug names and drug dosages), and is not responsible for any error and/or omissions arising from translation and adaptation or otherwise.

Open access This is an open access article distributed in accordance with the Creative Commons Attribution Non Commercial (CC BY-NC 4.0) license, which permits others to distribute, remix, adapt, build upon this work non-commercially, and license their derivative works on different terms, provided the original work is properly cited, appropriate credit is given, any changes made indicated, and the use is non-commercial. See: http://creativecommons.org/licenses/by-nc/4.0/.

\section{ORCID iDs}

Claire Khouja http://orcid.org/0000-0002-9571-3147

Dylan Kneale http://orcid.org/0000-0002-7016-978X

\section{REFERENCES}

1 Barker M. Pakistan province tells Red Bull and its rivals to drop 'energy' tag, in The Guardian. UK, 2018.

2 Committee on Nutrition and the Council on Sports Medicine and Fitness. Sports drinks and energy drinks for children and adolescents: are they appropriate? Pediatrics 2011;127:1182-9.

3 Smithers R. Uk supermarkets ban sales of energy drinks to under16s, in the Guardian. UK, 2018.

4 Cox J. Aldi and Asda become latest supermarkets to ban sale of high-caffeine energy drinks to under 16s, in Independent. UK, 2018.

5 UK Government.. Food labelling and packaging. food and drink warnings, 2021. https://www.gov.uk/food-labelling-and-packaging/ food-and-drink-warnings

6 EFSA. EFSA explains risk assessment: caffeine. Parma, Italy: European Food Standards Authority, 2015.

7 Haskell CF, Kennedy DO, Wesnes KA, et al. A double-blind, placebocontrolled, multi-dose evaluation of the acute behavioural effects of guaraná in humans. J Psychopharmacol 2007;21:65-70.

8 Keast RSJ, Swinburn BA, Sayompark D, et al. Caffeine increases sugar-sweetened beverage consumption in a free-living population: a randomised controlled trial. Br J Nutr 2015;113:366-71.

9 Curran CP, Marczinski CA. Taurine, caffeine, and energy drinks: reviewing the risks to the adolescent brain. Birth Defects Res 2017;109:1640-8.

10 Ruxton CHS. The suitability of caffeinated drinks for children: a systematic review of randomised controlled trials, observational studies and expert panel guidelines. J Hum Nutr Diet 2014;27:342-57.

11 Wikoff D, Welsh BT, Henderson R, et al. Systematic review of the potential adverse effects of caffeine consumption in healthy adults, pregnant women, adolescents, and children. Food Chem Toxicol 2017;109: :585-648.

12 Visram S, Cheetham M, Riby DM, et al. Consumption of energy drinks by children and young people: a rapid review examining evidence of physical effects and consumer attitudes. BMJ Open 2016;6:e010380.

13 Sabbagh D. Government to ban energy drink sales to children in England. The Guardian, 2018.

14 UK Government. Ending the sale of energy drinks to children, 2018. Available: https://www.gov.uk/government/consultations/ending-thesale-of-energy-drinks-to-children [Accessed 3 Apr 2020].

15 Department of Health and Social Care (DHSC). Banning the sale of energy drinks to children impact assessment, 2018.

16 Department of Health and Social Care. Energy drinks and children: government response to Science and Technology Committee report, D.o.H.a.S.C. (DHSC) eds. London, UK: Gov.UK, 2019.

17 Brunton G, Kneale D, Sowden A, et al. Caffeinated energy drinks and effects in young people: a secondary analysis of population-level datasets: review protocol. London: EPPI-Centre, Social Science Research Unit, UCL Institute of Education, 2018.

18 Brunton G, Khouja C, Raine G, et al. Caffeinated energy drink use and reported effects in young people: a rapid overview of systematic reviews. London EPPI-Centre, Social Science Research Unit, UCL Institute of Education, University College London; 2019.

19 Thomas J, Brunton J, Graziosi S. EPPI-Reviewer 4.0: software for research synthesis. London: Social Science Research Unit, Institute of Education, University of London, 2010.

20 StataCorp. Stata statistical software: release 13, 2013 
21 Uk data service. Available: https://ukdataservice.ac.uk/ [Accessed 3 Apr 2020].

22 Lanza ST, Dziak J, Huang L, et al. Lca Stata plugin users' guide (version 1.2, 2015.

23 Shea BJ, Reeves BC, Wells G, et al. AMSTAR 2: a critical appraisal tool for systematic reviews that include randomised or nonrandomised studies of healthcare interventions, or both. BMJ 2017;358: :j4008.

24 Brennan S, McKenzie J, Middleton P. Developing GRADE guidance for overviews of systematic reviews, in Global Evidence Summit. Cape Town, South Africa., 2017.

25 Pieper D, Antoine S-L, Mathes T, et al. Systematic review finds overlapping reviews were not mentioned in every other overview. $J$ Clin Epidemiol 2014;67:368-75.

26 McKenzie JE, Brennan SE. Overviews of systematic reviews: great promise, greater challenge. Syst Rev 2017;6:185.

27 UK Data Service. Quality assurance, 2020. Available: https://www. ukdataservice.ac.uk/manage-data/format/quality.aspx. [Accessed 8 Jun 2020].

28 National Institutes of Health. Quality assessment tool for observational cohort and cross-sectional studies., 2014. Available: https://www.nhlbi.nih.gov/health-topics/study-quality-assessmenttools

29 Alhyas L, El Kashef A, AlGhaferi H. Energy drinks in the Gulf Cooperation Council States: a review. JRSM Open 2016;7:2054270415593717

30 Dawodu A, Cleaver K. Behavioural correlates of energy drink consumption among adolescents: a review of the literature. J Child Health Care 2017;21:446-62.

31 Roemer A, Stockwell T. Alcohol mixed with energy drinks and risk of injury: a systematic review. J Stud Alcohol Drugs 2017;78:175-83.

32 Verster JC, Benson S, Johnson SJ, et al. Alcohol mixed with energy drink (AMED): a critical review and meta-analysis. Hum Psychopharmacol 2018;33:e2650.

33 Verster JC, Koenig J. Caffeine intake and its sources: a review of national representative studies. Crit Rev Food Sci Nutr 2018;58:1250-9.

34 Ali F, Rehman H, Babayan Z, et al. Energy drinks and their adverse health effects: a systematic review of the current evidence. Postgrad Med 2015;127:308-22.

35 Bleich SN, Vercammen KA. The negative impact of sugar-sweetened beverages on children's health: an update of the literature. BMC Obes 2018;5:6

36 Buck R. Energy drink consumption among adolescents and young adults: health effects and implications for practice. Westminster College, 2013.

37 Bull S, Brown T, Burnett K, et al. Extensive literature search as preparatory work for the safety assessment for caffeine. 12. EFSA External Scientific Report., 2015.

38 Goldfarb M, Tellier C, Thanassoulis G. Review of published cases of adverse cardiovascular events after ingestion of energy drinks. Am J Cardiol 2014;113:168-72.

39 Lippi G, Cervellin G, Sanchis-Gomar F. Energy drinks and myocardial ischemia: a review of case reports. Cardiovasc Toxicol 2016;16:207-12.

40 Richards G, Smith AP. A review of energy drinks and mental health, with a focus on stress, anxiety, and depression. J Caffeine Res 2016;6:49-63.

41 Yasuma N, Imamura K, Watanabe K, et al. Association between energy drink consumption and substance use in adolescence: a systematic review of prospective cohort studies. Drug Alcohol Depend 2021;219:108470.

42 Nadeem IM, Shanmugaraj A, Sakha S, et al. Energy drinks and their adverse health effects: a systematic review and meta-analysis. Sports Health 2021;13:265-77.

43 University of London, I.o.E., Centre for Longitudinal Studies,. Millennium cohort study: fourth survey,, 2008. Available: https:// cls.ucl.ac.uk/cls-studies/millennium-cohort-study/ [Accessed $3 \mathrm{Apr}$ 2020].

44 Richards G. Caffeinated energy drink use in adolescents and young adults: associations with mental health, academic performance, and problem behaviour [PhD Thesis]. Cardiff University, 2016.

45 Richards G, Smith AP. Breakfast and energy drink consumption in secondary school children: breakfast omission, in isolation or in combination with frequent energy drink use, is associated with stress, anxiety, and depression cross-sectionally, but not at 6-month follow-up. Front Psychol 2016;7:106.

46 Richards G, Smith AP. Associations between energy drink consumption and school attendance, academic attainment, and problem behaviour: a cross-sectional and longitudinal analysis. Lancet 2016;388:S101.

47 EFSA Panel on Dietetic Products, Nutrition and Allergies (NDA). Scientific opinion on the safety of caffeine. EFSA Journal 2015;13:4102.

48 Kilani H, Al-Hazzaa H, Waly Ml, et al. Lifestyle habits: diet, physical activity and sleep duration among Omani adolescents. Sultan Qaboos Univ Med J 2013;13:510-9.

49 Nowak D, Jasionowski A. Analysis of the consumption of caffeinated energy drinks among Polish adolescents. Int J Environ Res Public Health 2015;12:7910-21.

50 Flotta D, Micò R, Nobile CGA, et al. Consumption of energy drinks, alcohol, and alcohol-mixed energy drinks among Italian adolescents. Alcohol Clin Exp Res 2014;38:1654-61.

51 NHS Digital. Smoking, drinking and drug use among young people in England, 2014. Available: https://digital.nhs.uk/data-and-information/ publications/statistical/smoking-drinking-and-drug-use-amongyoung-people-in-england/2014 [Accessed 8 Jun 2020].

52 Gambon DL, Brand HS, Boutkabout C, et al. Patterns in consumption of potentially erosive beverages among adolescent school children in the Netherlands. Int Dent J 2011;61:247-51.

53 Reid JL, Hammond D, McCrory C, et al. Use of caffeinated energy drinks among secondary school students in Ontario: prevalence and correlates of using energy drinks and mixing with alcohol. Can J Public Health 2015;106:e101-8.

54 Bryant Ludden A, Wolfson AR. Understanding adolescent caffeine use: connecting use patterns with expectancies, reasons, and sleep. Health Educ Behav 2010;37:330-42.

55 O'Dea JA, O'Dea JA. Consumption of nutritional supplements among adolescents: usage and perceived benefits. Health Educ Res 2003;18:98-107.

56 Musaiger AO, Zagzoog N. Knowledge, attitudes and practices toward energy drinks among adolescents in Saudi Arabia. Glob J Health Sci 2014;6:42-6.

57 Gallimberti L, Buja A, Chindamo S, et al. Energy drink consumption in children and early adolescents. Eur J Pediatr 2013;172:10.1007/ s00431-013-2036-1:1335-40.

58 Abian-Vicen J, Puente C, Salinero JJ, et al. A caffeinated energy drink improves jump performance in adolescent basketball players. Amino Acids 2014;46:1333-41.

59 Gallo-Salazar C, Areces F, Abián-Vicén J, et al. Enhancing physical performance in elite junior tennis players with a caffeinated energy drink. Int J Sports Physiol Perform 2015;10:305-10.

60 Temple JL, Dewey AM, Briatico LN. Effects of acute caffeine administration on adolescents. Exp Clin Psychopharmacol 2010;18:510-20.

61 Wing YK, Chan NY, Man Yu MW, et al. A school-based sleep education program for adolescents: a cluster randomized trial. Pediatrics 2015;135:10.1542/peds.2014-2419:e635-43.

62 Hartley JEK, Levin K, Currie C. A new version of the HBSC Family Affluence Scale - FAS III: Scottish Qualitative Findings from the International FAS Development Study. Child Indic Res 2016;9:233-45.

63 Zucconi S, Volpato C, Adinolfi F, et al. Gathering consumption data on specific consumer groups of energy drinks. EFSA Supporting Publications 2013;10:10.2903/sp.efsa.2013.EN-394.

64 Seifert SM, Schaechter JL, Hershorin ER, et al. Health effects of energy drinks on children, adolescents, and young adults. Pediatrics 2011;127:511-28.

65 NHS Wales. Health behaviour in school-aged children (HBSC), 2018. Available: http://www.publichealthwalesobservatory.wales.nhs.uk/ HBSC. [Accessed 8 Jun 2020].

66 Public Health England. National diet and nutrition survey, 2016. Available: https://www.gov.uk/government/collections/national-dietand-nutrition-survey [Accessed 8 Jun 2020].

67 Northern Ireland Statistics and Research Agency. Young Persons' Behaviour and Attitudes Survey, 2016. Available: https://www. nisra.gov.uk/statistics/find-your-survey/young-persons-behaviourattitudes-survey. [Accessed 8 Jun 2020]. 